IJMS 2017 vol. 4 (2): 1 - 7

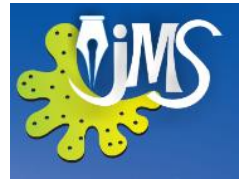

International Journal of Multidisciplinary

Studies (IJMS)

Volume 4, Issue 2, 2017

DOI: http://doi.org/10.4038/ijms.v4i2.17

\title{
Need for Transformative Adaptation in South Asia
}

\author{
Madhav Karki \\ Deputy Chair, Commission on Ecosystem Management, Nepal
}

\begin{abstract}
South Asia region is one of the most vulnerable to climate induced hazards and risks. A recent ADB publication predicts that the region is at risk of losing up to $8.8 \%$ GDP due to climate change by the end of the century. Climate change directly or indirectly affects all sectors of economy and livelihoods of nations and communities requiring adaptation, mitigation and disaster risk reduction measures so as to reduce and manage increasing risks and stresses. It is therefore logical that all of the South Asian countries have placed adaptation issues on high priority - many already mainstreaming and integrating climate change risks in their socio-economic development policies, plans and programs. Synergy is also gradually developing among sustainable development, environmental conservation and climate change adaptation including disaster risk reduction. Developing capacity of the closely interwoven socio-agro-ecological systems that prevail in South Asia seem to be the running thread among these three important pillars of human development and nature conservation. Recognizing that climate change is one of the newest drivers of change, this paper describes why the current state of scattered, fragmented and micro scale adaptation work in the region need to scale up and scale-out for building a resilient and prosperous South Asia. Multiple approaches are adopted and practiced to design and implement adaptation programs. Participatory visioning and planning of adaptation goal and action is an accepted practice in South Asia countries that are reflected in most of the community-based and ecosystem based adaptation (CBA and EbA) work being undertaken by governmental, non-governmental and community based agencies. However, these local plans are confined to limited budget, geography, population and scope often aimed at reducing the direct and urgent impacts. Given that climate change impacts are not limited to any administrative, ecological and political boundaries as well as it has slow onset process, there is a need to upscale (vertically to policies and programmes) as well as out-scale (horizontally) to larger areas, population and landscape to make adaptation sustainable and resilient to deal with increasing frequency and severity of climate induced risks and hazards. For a tangible and sustained adaptation impact, emphasis need to be laid on identifying innovative ideas and practices that contribute towards improved ecosystem and social services, help make infrastructures more climate resilient, and human development more sustainable. This way, we can achieve adaptation at scale which can also help achieve transformative adaptation. In fact, scaled-up and scale-out and transformative adaptation work underpin sustainable development and biodiversity conservation that can help South Asian countries achieve both Sustainable Development Goals and Aichi Biodiversity Targets.
\end{abstract}

KEYWORDS: Vulnerable communities, adaptation, disaster risk reduction, transformative adaptation, diverse of change, sustainable development

Corresponding author: Madhav Karki, Email: karki.madhav@gmail.com 


\section{BACKGROUND AND INTRODUCTION}

South Asia is one of the most vulnerable subcontinents to climate change. Rapid melting of Himalayan glaciers, increasing frequency and intensity of extreme events such as floods, droughts and cyclones followed by unprecedented hydrological disasters and damages to lives and properties mean that South Asian population has to scale-up and scale-out on-going adaptation efforts. Scaling up and scaling out are emerging concepts on adaptation planning and implementation to respond to growing climatic and non-climatic vulnerabilities faced by poor, disadvantaged and resource poor households and communities. It focuses on scale, skill, and speed that are the attributes of transformative adaptation. It is an idea that goes beyond the business as usual (BAU) adaptation approach which in most of the South Asian countries is characterised by unplanned or autonomous adaptation. The transformative adaptation is based on innovative, novel and game-changing idea. Policy makers and donors at all levels are pressing for adaptation solutions that are scalable and transformational in response to rapidly changing nature and scale of the climate vulnerability and impact. Many governments are reforming policies to encourage scalable adaptation (e.g. National Adaptation Plan or NAP) because upscaling and out-scaling are necessary for mobilising maximum adaptation funding from development partners and generating benefits to vulnerable communities, people and their physical and organizational assets.

\subsection{Why current adaptation efforts need to scale-up and be transformative?}

Most of on-going adaptation interventions in South Asia and elsewhere in developing countries involve incremental approaches intended to protect and sustain existing systems and practices. A recent review by OXFAM (Sterrett, C, 2011) concluded that "adaptation efforts in South Asia have so far been fragmented, lacking a strong link between national climate change strategies and plans, and existing disaster risk reduction, agricultural, and other relevant policies". For example community based adaptation (CBA) is commonly practiced in most of the SAARC countries which remains narrow focused on soft measures such as capacity building and institutional coordination. In recent years, there is move to promote new breed of adaptation that is popularly known as Ecosystem based adaptation or EbA.

\subsection{What are EbA and CBA?}

The CBD expert group has defined EbA as 'the use of biodiversity and ecosystem services to help people adapt to the adverse effects of climate change' (CBS, 2010). The approach includes 'sustainable management, conservation and restoration of ecosystems, as part of an overall adaptation strategy that takes into account the multiple social, economic and cultural co-benefits for local communities' . Typical EbA activities and benefits accrued include: a) maintaining and restoring "natural infrastructure" such as critical watersheds; b) protecting and restoring natural areas of cultural or religious significance, c) enhancing the availability of natural resources as a source of food, water and biodiversity; d) supporting indigenous peoples and local communities to adapt to climate change; and e) maintaining connectivity of ecosystems in production landscapes to provide habitats for threatened floras and faunas.

Community-Based Adaptation (CBA) has been defined as, "a community-led process, based on communities' priorities, needs, knowledge and capacities, which should empower people to plan for and cope with the impacts of climate change." (Reid et al., 2009). It is also known as the Human Rights Based approach to climate change adaptation (CCA). Typical CBA activities include: a) livelihoods resilience (examples: drought tolerant crops, income diversification etc.); b) disaster risk reduction to minimize the impact of hazards; c) capacity strengthening of local civil society and government institutions; 
and d) advocacy and social mobilization to address the underlying causes of vulnerability, including poor governance.

\section{LIMITATIONS OF EBA AND CBA}

Recognizing the integral relationship between ecosystems and livelihoods and the threat and risk of climate change to the vulnerable communities and fragile ecosystems, EBA is being promoted by conservation and development organisations especially in mountains and coastal areas in South Asia. Many successful case studies and pilots exist in EbA but most of them lack scientific vulnerability assessment and robust evidence of their effectiveness to address the climate driven risks and hazards. There are also few case studies on either the cost-effectiveness of EbA or on the assessment of its social value since most impacts of climate change often disproportionately affect the most vulnerable communities. There are also scattered literature and knowledge gaps with respect to EbA. Empirical materials relevant to $\mathrm{EbA}$ are dispersed in forest and natural resource management, disaster risk reduction and agroecology. Evidence and lessons learnt from these disciplines have not been well collated and widely shared to inform decision makers to decide on best adaptation options. It is felt that EBA assumes that extant ecosystems deliver services on which people depend indicating a need for more emphasis on human-capacity building as done by the CBA.

CBA also has a number of limitations. For example, a majority of people in mountain, coast land and dry land contexts depend on ecosystem goods and services. But CBA does not directly consider improving the quality and quantity of ecosystem goods and services or natural resources as well as biodiversity explicitly while designing adaptation strategies. CBA also does not consider improving the human induced management capacity building to improve and sustain the flow of specific ecosystem services (e.g. forest products).

\section{NEED FOR INTEGRATING EBA, CBA AND DRR THROUGH TRANSFORMATIVE ADAPTATION}

Conceptually, all adaptation tools especially CBA and EBA but also the disaster risk reduction measures are people-centred and aim at reducing the damage to lives and livelihoods. Since in South Asia over $60 \%$ of the population draw their livelihoods from Agriculture including natural resources, ensuring sustained flow of ecosystem goods and services is must in people-centred adaptation. Such adaptation should aim to scale up and advocate communitydriven process and address ecological and social complexity prevailing in a particular locality or an ecosystem. There is a need to recognize the relevance of local specificities since adaptation is essentially and inevitably done at local scale. Integrated approaches in which both society and nature based solutions are packaged under one umbrella adaptation scheme have a better chance to forcefully address shortcomings of not only the EbA and CBA but also others. Such an adaptation is both people and ecosystem-centred adaptation which is defined as "adaptation planning and action that adheres both to human rights-based principles and principles of sound environmental management and successfully manage climate variability and long-term change" (ELAN, 2010). This is close to what IPCC calls a Transformative Adaptation.

\section{APPROACH TO TRANSFORMATIVE ADAPTATION}

Transformative adaptation is defined as "Adaptation that changes the fundamental attributes of a system in response to climate and its effects", (IPCC, 2014). Scaled-up adaptation leads to "more quality benefits to more people over a wider geographic area more quickly, more equitably and more lastingly". This is a vertical process and involves expansion from grassroots organizations to local, sub-national to national institutions and policies. Scaled-out adaptation involves activities that show expansion in 
quantitative scale and/or size covering more partners and beneficiaries in larger geographical areas spending higher budgets.

More than one process can happen at the same time. Scaling up is using knowledge, information, capacity and lessons learned from good adaptation practices to inform local, provincial and national-level policies, plans, programs and also leads to network formation. Scaled-out adaptation benefits more people in more vulnerable communities, in significantly larger numbers quickly, equitably, and lastingly. It is a horizontal process that refers to geographical spread or replication on a larger beneficiary scale, from hundreds to thousands or millions of people. This shows that transformative and scaled-up and scaled-out adaptation solutions are both complimentary and synergistic.

\section{PATHWAYS FOR TRANSFORMATIVE OR SCALED-UP ADAPTATION}

As mentioned above, transformative adaptation leads to "more quality benefits to more people over a wider geographic area in a faster, more inclusive and more sustainable manner compared to comparable work." It is both a vertical and horizontal process and involves expansion from the level of grassroots organizations, villages to municipalities, provinces, and country level institutions and policies. For example transformation of ecosystems will be a permanent shift to an alternative stable ecosystem state and can be characterised by resilient socio-ecological systems based on resilient thinking (Walker et al., 2004).

In a transformed ecosystem, goods and services are more aligned to the needs of both the concerned society and ecology. Transformation of decision making system in adaptation is characterized by: a) network based partners; b) multiple source of knowledge, and c) equitable access to resource (Gorddard et al., 2016) which are vital elements in the A@SP project activities.

\section{TRANSFORMATIVE ADAPTATION NEEDS TRANSFORMATION CAPACITY DEVELOPMENT}

In climate change adaptation, evidence from the ground (WRI, 2015) indicates that currently available capacity building efforts are fragmented, scattered and spread out too thin. However, new and enhanced capacity is essential to enable the type of change that can help stakeholders to negotiate co-management and engage in co-production (e.g. PES mechanism) or benefit from climate services and technological support (e.g. Chaffin et al., 2016). Therefore, transformative adaptation, first and foremost, will need transformative capacity development and adaptive and transformative governance. This will prepare the partners to undertake the type of change that enables them to design and implement transformative adaptation. For example, socio-economic and ecosystem based adaptation (EbA) opportunities requires specific types of capacity for multihazard based vulnerability impact assessment, biodiversity conservation and ecosystem management (Dixit, Karki et al., 2015). Similarly, CBA requires community mobilization and social and environmental awareness raising and adaptive capacity building.

Policy makers, adaptation managers, capacity building organizations including universities in South Asia should proactively develop and enhance cross-sectoral partnerships and rapid learning to promote transformational approaches to adaptation. Since climate change vulnerability and impacts are becoming more severe every year, especially in highly vulnerable countries like Sri Lanka, Bangladesh, Nepal, and Afghanistan, adaptation has to go beyond the business as usual (BAU) approach and move in the trajectory of transformational pathways. South Asian countries need adaptation that seeks to replace fragile systems with new or functional ones to better meet the unpredictable nature of future climatic change. Most of the adaptation work currently being undertaken in the above 
countries aims at doing incremental adaptation but most of them fail to achieve what they set out to accomplish. These activities essentially try to fill in identified 'adaptation deficiencies', or 'gaps' and in this effort also, most of the initiatives fail to achieve the expected outcomes as adaptation needs are constantly outpacing the adaptation responses. This is actually why we need scaling-up and scaling-out to fill in the expanding gap and to be able to achieve the transformative quality of adaptation that the IPCC recommended way back in 2014 (IPCC, 2014).

\section{CONCLUSION}

Climate change adaptation is a national priority for South Asia. But current adaptation activities are fragmented, scattered and output based. They are incoherent as shown by plethora of acronyms: EbA, CBA and DM, DRR and others. Obviously these activities also have overlaps and redundancy. There is an urgent need to plan adaptation in line with sustainable development as clearly demonstrated by the UN's sustainable development goals (SDG). Mountain EbA in Nepal has been rightly called the Paristhikiya Pranalima Adharit Anukulan (Socio-ecological system based adaptation), which is the recognition of the specificities of mountain societies and their uniqueness. Similarly, in the island nation of Sri Lanka, adaptation has to also be based on combined human-ecosystem and technology based framework. It can be therefore argued that transformative adaptation can promote holistic, integrated, adaptive, multiscale, multi-stakeholder and multi-disciplinary adaptation toward building resilient communities, ecosystems and country as a whole in South Asia. Some of the suggestions for moving on this transformative direction, especially in vulnerable countries such as Bangladesh, Nepal and Sri Lanka are outlined below.

1. Adaptation projects should be treated as components of the larger sustainable development programme and be integrated in the broader landscape-level environment and development programme from the very beginning;

2. Adaptation is an on-going process and essential should play complementary and a 'critical gap filling' role and be made part of larger government policy and programme;

3. Many of the current adaptation programmes are not very different from the traditional and government run initiatives (e.g. watershed management, catchment conservation and degraded land restoration) and programmes); future adaptation programmes therefore should not do more of the same but add value, sharpen focus and deepen the impact of the existing programmes.

4. Enabling regular and active participation of all the central agencies from Village and Municipality to the Centre is one of the key requirements for achieving adaptation impacts;

5. To become transformative adaptation initiatives must mobilise and engage all the communities in a landscape or river basin/subbasin level in a mass scale for ensuring outcome achievement;

6. Scaled-up adaptation activities are demand-based, mainstreamed, and integrated, and generate best practices that are both replicable and up-scalable;

7. Such activities have high local ownership (e.g. river training, degraded land restoration/rehabilitation, and water source protection work) and are operating under popular community forestry, local water management and smart agriculture programmes.

8. Finally, transformative adaptation interventions should have strong linkages with the concerned Government's flagship programmes such as the National Adaptation Plan of Action (NAPA), National Adaptation 
Plans (NAP); National Biodiversity Strategy and Action Plan (NBSAP) and Nationally Determined Contribution (NDC) of Paris Agreement; and Sustainable Forest Management.

\section{REFERENCES}

CBD. Introduction to Ecosystem-based Adaptation: A nature-based response to climate change; global ecosystem-based adaptation in mountains programme; 2010. Available at file:///E:/A@S/PDF/learningbriefnaturebasedres learningbriefnatureb.pdf.

DAGNET Y, NORTHROP E \& TIRPAK D. How to Strengthen the Insitutional Architecture for Capacity Building to Support the Post-2020 Climate Regime. Working Paper. Washington, DC: World Resources Institute. 2015. Available online http://www.wri.org/publications/capacitybuildin g

DIXIT A, KARKI $M$ \& SHUKLA AK. Vulnerability Impact Assessment and Adaptation Planning in Panchase. Ecosystem Region Nepal. Kathmandu: Institute for Social and Environmental TransitionNepal/UNEP/UNDP/BMU; 2014. Available at http://reliefweb.int/report/nepal/vulnerabilityand-impacts-assessment-adaptation-planningpanchase-mountain-ecological; ISBN: 9789937-8519-2-3

ELAN. Building poor and marginalized people's resilience to the impacts of climate change by promoting sound ecosystem management within an integrated approach to adaptation policy and practice. Available at www.elanadapt.net

EVERETT B, BARNETT C AND VERMA R. Evidence Review - Environmental Innovation Prizes for Development. DEW Point Enquiry No. A0405. London, DFID. 2011.
GOGOI E, DUPAR M, JONES L, MARTINEZ C \& MCNAMARA L. CDKN. How to scale out community-based adaptation to climate change. Working Paper. 2014. Available at www.cdkn.org.

HUYER S, HANSEN J, ROSE A, VAUGHAN $\mathrm{C} \&$ VAN HUYSEN T. What We Know about Gender and Rural Climate Services. Info Note: Preliminary Findings and Guidance. CGIAR/CCAFS; 2017. Available at https://cgspace.cgiar.org/rest/bitstreams/146698 /retrieve

IPCC. Climate change 2014: Impacts, adaptation, and vulnerability. Contribution of Working Group II to the Fifth Assessment Report of the Intergovernmental Panel on Climate Change. IPCC, Geneva, Switzerland. 2014.

LONSDALE K, PRINGLE P \& TURNER B. Transformative adaptation: what it is, why it matters \& what is needed. UK Climate Impacts Programme, University of Oxford, Oxford, UK. 2015. ISBN: 978-1-906360-11-5; C UKCIP 2015

MADHAV K, MOOL $\mathrm{P}$ \& SHRESTHA A. Impacts of Climate Change on the Water and Ecological Security of the Himalayan Mountains and need for Adaptation through South-South Exchange. In: Climate Change and Water: Experiences from the Field. 2011. Available at http://ccwiwra.files.wordpress.com/2011/07/im pacts-of-climate-change-himalaya-andeanmountains.pdf

MADHAV K. Climate Change: Integrating Indigenous and Local Knowledge into Adaptation Policies and Practices: A Case Study from Nepal; Shifting Cultivation; CABI Publication (In Press). 2016.

MAHFUZ A \& SUPHACHOL S. ADB. Assessing the Costs of Climate Change and Adaptation in South Asia. ISBN 978-92-9254510-9 (Print); 978-92-9254-511-6 (Electronic); 
2014.

Available

at

http://hdl.handle.net/11540/46.

MIPSIE M \& LARS NO. A Role for Innovation

Prizes to Support Adaptation to Climate Change?

An Analysis of Challenges, Opportunities and

Conditions; In a Development Context; Institute

of Development Studies; UK. 2015.

REID H \& HUQ S. Mainstreaming communitybased adaptation into national and local planning, Climate and Development. 2014; 6:4, 291-292, DOI: 10.1080/17565529.2014.973720 Available at

https://doi.org/10.1080/17565529.2014.973720

ROSSING T, OTZELBERGER A \& GIROT P. CARE. Scaling-up the use of tools for community-based adaptation: Issues and challenges. CARE International: Final draft submitted to Earthscan. 2012.

SELVARAJU R. FAO. Managing climate risks and adapting to climate change in the agriculture sector in Nepal Climate, Energy and Tenure Division (NRC); Food and Agriculture Organization of the United Nations (FAO); Rome, Italy. 2014.

STERRETT C. Review of Climate Change Adaptation Practices in South Asia, Oxfam Research Report, Climate Concern, Melbourne, Australia. 2011.

UNFCCC Adaptation planning, implementation and evaluation addressing ecosystems and areas such as water resources: Synthesis report by the secretariat; Summary; UNFCCC Secretariat, Bonn; FCCC/SBSTA/2017/3. 2017.

WALKER B, HOLLING CS, CARPENTER SR \& KINZIG A. Resilience, adaptability and transformability in social-ecological systems. Ecology and Society, 2014; 9(2): 5. 